\title{
The path to integration of psychiatry with the rest of medicine: is it via the heart?
}

\author{
R Abeyasinghe
}

Depression is a serious mental disorder that is most commonly treated by general practitioners in the developed world. In Sri Lanka it is poorly detected and hardly ever treated in primary care practice, despite a prevalence of $12.9 \%$ in primary care (1). Depression is the commonest cause of suicide, which is the $15^{\text {th }}$ cause of death in the world and was the $2^{\text {nd }}$ leading cause of death in the age group 15-29 years, in 2012 (2); but depression is often not seen as a disorder that needs to be screened for in all patients. Perhaps the stigma attached to disorders which bear the prefix "mental" accounts for this reluctance to accept depression as a real disease that needs active intervention. Anything “mental” is under one's will power, according Sri Lankan lay reasoning, shared by the Sri Lankan medical community. If suicide does not arouse any interest in the medical community, the findings that $38.9 \%$ of those who have suffered myocardial infarction have depression (3), and that depression is an independent risk for mortality in ischaemic heart disease (4), should do so. It has also been shown that treatment of depression reduces mortality risk after myocardial infarction by as much as $42 \%$ (5).

In this context, the scientific statement on depression issued recently by the American Heart Association (AHA), has an important bearing on Sri Lankan medical practice (6). By emphasizing depression as an important risk factor for heart disease and mortality related to heart disease, the AHA has made a case for screening for and treatment of depression in patients with heart disease. After a series of studies which showed that depression is an independent risk factor that caused higher mortality, the AHA took action in the form of appointing a panel to review all studies up to 2014 and to come up with recommendations. The panel reviewed 53 studies and 4 meta analyses that had studied depression and heart disease. There were 32 studies that reported on depression and mortality. The review found that 21 out 32 studies reported an increase in overall mortality. 12 studies had reported on mortality specific to heart disease and of these 8 had found a relationship with depression. All 4 meta analyses too established a similar relationship. The review also found that the somatic symptoms, presence of depression after a myocardial infarction, and a longer duration of depression resistant to treatment, carried a higher risk. They were unable to establish the rank relative to other risk factors for depression, since depression appeared to influence many other risk factors such as smoking and inactive life styles.
This panel also declared the need for more work in this area. Some of the areas that require further study would be whether depression is a direct risk for heart disease and how it causes increased mortality. There is also the possibility of a common genetic basis for diabetes mellitus, heart disease and depression.

We in psychiatry have reason to salute the interest shown by American Heart Association, as this is a good omen for the future of psychiatry. Such recommendations will lead to better integration with the rest of medicine and promote the relevance of mental disorders among the rest of the medical community, thus ending the isolation that began with the separation of patients and psychiatrists in mental asylums. More such relationships between mental and medical disorders need to be explored in order to promote closer integration.

R Abeyasinghe, Former Head \& Senior Lecturer, Department of Psychiatry, Faculty of Medicine, Peradeniya, Sri Lanka

Email: ranil52@gmail.com

\section{References}

1. Seneviratne R. Prevalence of depression in a general practice setting. MD thesis, Post Graduate Institute of Medicine, University of Colombo, Sri Lanka; 2012.

2. Preventing Suicide: a global imperative. World Health Organization 2014.

3. Monaragala RMM. Prevalence of depression in recent myocardial infarction: a hospital based study. MD thesis. Post Graduate Institute of Medicine, University of Colombo, Sri Lanka; 2008.

4. Ariyo AA, Haan M, Tangen CM, Rutledge JC. Depressive symptoms and risks of coronary heart disease and mortality in elderly American. Circulation. 2000; 102(15): 1773-9.

5. Taylor CB, Youngblood ME, Catellier D, et al. Effects of antidepressant medication on morbidity and mortality in depressed patients after myocardial infarction. Arch Gen Psychiatry 2005; 62: 792-8.

6. Judith H, Lichtman, Erika S, et al. Depression as a Risk Factor for Poor Prognosis Among Patients With Acute Coronary Syndrome: Systematic Review and Recommendations: A Scientific Statement From the American Heart Association. Circulation 2014; 129: 1350-69 